\title{
Preference reversal, real-world lotteries, and lottery-interested subjects
}

\section{Peter Bohm and Hans Lind*}

\author{
Stockholm University, Stockholm, Sweden
}

Received February 1992, final version received August 1992

Prefersuce reversal, or choice/reservation-price inconsistency, has been dccumented experimentally for sertain types of lotteries. We argue that the relevance of these findings for real-world markets is uncertain because the type of objects used cannot exist on a market and because the extent to which the subjects had any real interest in the objects is unknown. Using real-world lotteries, we have tested choice/price consistency on subjects who prefer lotteries to cash. Preference reversal was observed, but the frequency was much lower than in earlier experiments. There were no differences between subjects who qualified as 'lottery interested' and those who did not.

\section{Introduction}

Preference reversal has been documented experimentally for certain types of lotteries, decision-makers and environments. ${ }^{1}$ The most common type of preference reversal is where subjects (a) choose a lottery with a high probability of winning a low amount (a 'P-bet') over a lottery with a low probability of winning a high amount (a ' $\$$-bet') and (b) state a higher selling price for the \$-bet than for the P-bet. Thus, if choice and reservation prices are viewed as two forms of preference expression, individual preferences seem to depend on what form is used, implying that preferences may be reversed when shifting from one form to another. Such behavior is inconsistent with standard microeconomic theory and expected utility theory.

Since the robust evidence of preference reversal is limited to specific situations and, in particular, since some writers on the subject have

Correspondence to: Peter Bohm, Department of Economics, Stockholm University, S-106 91 Stockholm, Sweden.

*Professor and Assistant Professor of Economics, respectively, Department of Economics, Stockholm University, S-106 91 Stockholm, Sweden. We would like to thank Lars Vahtrik and Mats Kinnwall for assistance in carrying out the experiments presented here. Financial support from the Bank of Sweden Tercentenary Foundation is gratefully acknowledged.

${ }^{1}$ The classic study by economists is Grether and Plott (1979), which was a critical replication of the studies by Slovic and Lichtenstein (1968) and Lichtenstein and Slovic (1971). Other important studies are those by Pommerehne et al. (1982) and Berg et al. (1985). Recent studies include Cox and Epstein (1989), Tversky et al. (1990) and Bostic et al. (1990). 
interpreted this evidence as damaging to standard theory of decision making under uncertainty in general [e.g., Grether and Plott $(1969$, p. 623), Siovic and Lichtenstein (1983, p. 602) and Tversky and Thaler (1990, p. 20\%)], the question arises to what extent preference reversal does exist for other types of objects, decision makers and environments. In particular, to what extent can preference reversal be observed in markets concerning reguiar investment alternatives, durable goods, and other objects with uncertain payoffs? In a recent experiment with used cars as payoff-uncertain choice objects instead of lotteries, and with participants who had revealed an interest in buying a used car, no preference reversal was observed [Bohm (1991)]. Now, given that preference reversal - to our knowledge - has been observed only for certain lotteries that do not exist on regular lottery markets (see below), we ask: Does preference reversal arise for lotteries that do exist on the market (realworld lotteries, for short)?

In response to this question we should note two important facts. First, the extent to which the subjects used in laboratory lottery experiments were representative of real-world lottery consumers is unknown. With the exception of Lichtenstein and Slovic (1973), it has not been documented that the subjects were interested in the type of objects used in the experiments, e.g., by being at least occasional buyers of lottery ticikets, let alone buyers of anything close to the quite special lottery tickets used in the experiments. ${ }^{2}$ This means that subjects who revers? preferences may be individuals who otherwise would not buy (these or any other) lottery tickets and, thus, that preference reversal would be a miner problem for a theory about behavior in real-world lottery markets.

Second, the lotteries used in previous experiments have been of a type that cannot be found in the market. They have differed from most non-laboratory lotteries in several respects.

- The laboratory lotteries had positive expected values, while real-world lotteries are sold for a profit and therefore have negative expected values for the buyers. In particular, it should be noted that lotteries of the P-bet type used in earlier experiments simply could not exist on a real-world lottery market. In a typical P-bet, the subject is given \$5 with a probability of 0.9 . Then, since the surn of prizes for most lotteries is far below 100 percent of gross receipts, iypically perhaps around 50 percent, this bet would have to be sold for around \$9. It is hardly possible to find anyone who would pay \$9 for a lottery ticket what would give $\$ 5$ with the probability 0.9 !

- The laboratory lotteries used one or two prizes only, whereas most or all

\footnotetext{
${ }^{2}$ In the oft-quoted Las Vegas experiment reported in Lichienstein and Slovic (1973), subjects were ordinary casino patrons - presumably gamblers - who volunteered to participate. However indisputable the value of this rare nonhypothelical test is, it should be noted that (a) the games offered were new and of the on z-prize type, and (b) the expected payoff of each new round of lotteries for subjects to choose among was zero.
} 
non-laboratory lotteries have complex prize plans, i.e., several prizes with different probabilities.

Here, we report on a set of experiments with real-world lotteries ${ }^{3}$ and with subjects who reveal whether or not they prefer lotteries to money. More specifically, we investigate

(1) whether preferences reversal is equally frequent with real-world lotteries as with the type of lotteries used in earlier experiments;

(2) whether preference reversal is equally frequent among those who indicate an interest in lotteries as among those who do not;

(3) whether preference reversal, to the extent it arises, shows the same pattern for real-world lotteries and lottery-interested subjects as in earlier experiments, in particular a higher share of preference reversal among those who choose the P-bet than among those who choose the S-bet.

In addition, we test behavior concerning lotteries with a structure similar to that used in previous laboratory experiments - a single prize - but with probabilities of winning and expected payoffs similar to those of real-world lotteries. This behavior is then compared with that of the subjects in previous experiments and in our experiment with real-world lotteries.

In the next section we outline the basic design of our experiments. In section 3 we discuss how the design relates to that of earlier experiments. The details of the experimental procedure are presented in section 4, the results in section 5 and concluding comments in section 6 .

\section{The basic experimental design}

It turned out to be easy to find sufficiently different real-world lotteries which could be interpreted as representations of the P-bet type and the \$-bet type. We used two well-known Swedish state lotteries for this purpose. However, straightforward experimental use of these or any other real-world lottery tickets did not seem appropriate here. The primary reason is that such iotteries are for sale 'everywhere' and hence can be bought outside the premises of an experiment for the given market price. This would affect both buying reservation prices and selling reservation prices. Under the given conditions, no one can really be expected to be willing to buy at a price above the market price, and most people should be willing to sell at any price above the market price. Thus, reservation prices for these lottery tickets could not be expected to provide information about lottery preferences. ${ }^{4}$

Since, for the reasons just given, it seemed unwise to use real-world lottery tickets as they are, we chose to use shares of packages of real-world lottery

\footnotetext{
${ }^{3}$ For reasons given in section 2 compounds of real-world lotteries were used in these experiments.

${ }^{4}$ This problem sometimes appears to be neglected, e.g. in the 'mug experiments' presented by Kahneman, Knetsch and Thaler (1990).
} 
tickets. Such shares are a form of real-world lotteries, but one that cannut be bought rough and ready on an outside market.

In addition to using real-world objects, we designed our test so as to reveal whether or not participants were 'interested' in lotteries, i.e., whether or not they were decision-makers to whom the theory in question should be particularly applicable. Here, we recruited a group of students in much the same way as in other experiments, but allowed them, in a first round of the experiment, to choose between lottery tickets and no sey with certainty more specifically, money in the amount of the price of the lottery tickets. Those who chose a lottery ticket in such a situation could be interpreted as being interested in lotteries, since they were willing to give up money for a lottery ticket just as a real-world lottery consumer does. The experiment would thus allow us to cumpare the behavior of those who choose cash and those who choose a lottery ticket in the first round. The lat er group is called 'interested subjects' in the rest of the paper.

In the first round of the experiments, participants were given the opportunity to choose among three alternatives:

- a sum of money with certainty (SEK 40, approximately equal to \$7),

- a share of a package with P-bet lottery tickets and

- a share of a package with \$-bet lottery tickets.

The ticket-price value of each of these packages was equal to the cash amount. After this choice was made, participants were informed that, in addition, they would receive their preferred choices between the two remaining alternatives. In this way, a ranking of all three alternatives was obtained.

At the end of the first part of the experiment, participants were told that they would also be giveii the third alternative, and that they would now have an opportunity to sell one or both of the lottery shares they had been given and/or buy an additional share. More specifically, participants were asked to state at what prices they were willing to sell and at what prices they were willing to buy. Given their buying and selling reservation prices, equilibrium prices were established and lottery shares were bought anc sold at these prices. The choice in the first part of the experiment and the order of the reservation selling prices in the second part were then compared.

This experimental design may cause some problems. One has to do with income effects of the fact that between the time the participants chose their first lottery and the time they state their selling prices, they have also acquired a pair of shares of lottery tickets with a total market value of SEK 80, and (possibly) an additional SEK 40. However, this change in income is small and therefore unlikely to affect the order of the selling reservation prices. Another potential complication concerns the composition of the individual's wealth at the time when he makes his choices as compared to the time when he states his reservation prices. For example, it is possible that an individual might prefer the P-bet over the \$-bet; but prefer 
SEK $40+\$$-bet over SEK $40+$ P-bet. We return to this problem in section 5.3 , where we show that it dues not jeopardize our interpretation of the test results.

\section{Deviations from the design of earlier experiments}

\subsection{Non-hypothetical choices and significant object values}

In most preference reversal experiments subjects make a large number of choices, only some of which have real consequences. By some random mechanism it is then decided which lotteries will be played for real and which will remain hypothetical. Such a design lowers the expected payoff related to each choice, often down to quite insignificant levels. ${ }^{5}$ By contrast, the value of the alternatives in our experiment is fairly high (a market value of SEK 40 for each alternative). In addition, and more importantly perhaps, all choices are for real.

\subsection{Real-world prize pians, well-known lotteries, and non-trivial prizes}

All previous preference reversal tests we have seen have used lotteries that are not found in the real world. In particular, there has typically been one or two prizes, each of a modest size. By contrast, our experiment refers to state lotteries whose existence and general terms are well known. The prize plans of these lotteries contain at least seven prize sizes, some of which are quite high, as is typical of attractive real-world lotteries.

\subsection{Real sales and a market with a real demand side}

Over time, the literature on preference reversal has undergone a somewhat strange development. In the early literature, summarized by Grether and Plott (1979) and well represented by their own experiments, the basic issue was consistency between choice and the ranking of reservation prices. By contrast, more recently, Cox and Epstein (1989) and Tversky et al. (1990) use the prices elicited from each participant only for selecting which lottery (if any) he is given the opportunity to play. Lottery tickets are not sold - or

\footnotetext{
${ }^{5}$ Tversky et al. (1990) is a case in point. They use nonetary incentives for a minor part of their tests. There, subjects have a 15 percent chance of actually taking part in a non-hypotietical round; if so, each pair of the bets that the indiviclual is confronted with has a $1 / 6$ chance of being selected for actual play. There is, in addition, $\approx 1 / 2$ chance that the choice between the two bets in each pair will be based on the subject's stated choice between them. Thus, when considering what choice to make between two bets, the individual has a $(15 / 100) \times(1 / 12)=1 / 80$ chance of playing the one selected. Taking the $\mathrm{f}$ air of bets with the highest expected payoffs (no. $1), \$ 3.88$ vis. \$4.96. we see that the subject is asked to consider a choice between a bet with an expected payoff of almost 5 cents and another with an expected payoff of a little more than 6 cents. A more general discussion of this problem can be found in Harrison (1989a and 1989b).
} 
bought - at all in these experiments. Thus, the experiments are not related to the basic issue of choice/reservation-price consistency. ${ }^{6}$ In our experiments, lottery tickets are actually bought and sold by the subjects.

Furthermore, the market for lottery tick ots in our experiments is organized differently than in earlier experiments where subjects were allowed to make real ticket sales. The traditional method - the so-called BDM procedure has been to draw a price randumly from a certain interval. ${ }^{7}$ Those who stated a selling price below this price sell their tickets at the random price, other participants keep their tickets. We rejected this method in order to avoid introducing elements that participants might regard as artificial. Instead, the demand side in our experiments is generated in a way that resembles the demand side on real markets, i.e., demand stems from people interested in buying the objects in question. ${ }^{8}$

\subsection{The role of indifference statements}

Grether and Plott (1979) observed the potential risk of 'spurious' preference reversal if subjects were forced to state preference between objects when in fact they were indifferent. it turned out, how ver, that few subjects actually used an option to state indifference ( 3 percent $r \mathrm{r}$ less in Grether and Plott's own study). In addition, it should be noted that when there are three choice objects, as in our experiments, the test would be significantly more complicated if the subjects were allowed to state indifference. (Instead of three alternatives there would have been seven.) This addition to complexity is hardly worthwhile since preference reversal defined as

$$
B \geq A \text { and } p^{R}(A)>p^{R}(B),
$$

( $p^{R}$ is reservation price) is as relevant for analysis as preference reversal defined as



The reason, of course, is that according to standard theory, deviating reservation prices, $p^{R}(A)>p^{R}(B)$, are inconsistent with not only strict preference, $B>A$, but also indifference, $B \sim A$. Hence, we interpret choice of $B$ over

${ }^{6}$ Cox and Epstein (1989) p. 409, write: The design of our experiments, and the patterns of reversals that they produce, both differ in essential ways from previous preference reversal experiments. Thus we will refer to the reversals that we observe as "choice reversals", as distinct from the traditional preference reversal phenomenon.' It is hard to see how this statement is consistent with calling the experiment a 'preference reversal experiment'.

${ }^{7}$ For details see, e.g., Grether and Plott (1979).

${ }^{8}$ The traditional procedure also results in compound lotteries that car. lead to spurious preference reversals, as shown by Karni and Safra (1987). For a discussion of similar problems arising in the context of our approach, see footnote 21. 
Table 1

Number of participants.

\begin{tabular}{lll}
\hline Department & $\begin{array}{l}\text { Experiment I: } \\
\text { Rea!-world lotteries }\end{array}$ & $\begin{array}{l}\text { Experiment II: } \\
\text { Control lotteries }\end{array}$ \\
\hline Mathematics & 35 & - \\
Surveying & 28 & 58 \\
Architecture & 23 & - \\
\hline
\end{tabular}

$A$ as preference for $B$ or indifference between $A$ and $B$. The term preference reversal, or inconsistency of choice and reservation prices, is then reserved for the case where the individual states a strictly lower selling price for the lottery ticket chosen first. ${ }^{9}$

\section{The experimental procedures}

\subsection{The participants}

No students of Economics were used as subjects. The participants were undergraduate students at the Department of Mathematics, Stockholm University, and at the Departments of Surveying and Architecture, Royal Institue of Technology (Stockholm). The students were contacted by us in class and were informed that they could sign up for participation in an experiment concerning behavior under uncertainty. They were told that they could earn money, but that no specific sum could be guaranteed since actual earnings would be determined by an element of chance. Although nothing was said about lotteries, the information given was likely to attract people interested in gambles, which was just what we wanted. ${ }^{10}$ Between 40 percent and 80 percent of those informed in the various classes signed up; about 85 percent of those registered showed up. The number of participants in each experiment is shown in table 1.

\footnotetext{
${ }^{9}$ By this definition of preference reversa', participants stating identical reservation prices will never he regarded as preference reversers (or violators of economic theory in some other similar respec:). There ate at least two reasons for choosing a definition with this implication. First, this can hardly represent a violation of standard theory as long as such behavior can be explained by the natural wish to state bids in even amounts, which, in the case of strict prefe:ence but 'almost indifference', could lead to this kind of response p.ttern; moreover, it is doubtful whether one could ever measure 'closeness to indifference' - except perhaps by using differences in reservation prices (!). Second, and perhaps more important, costs of identifying one's 'exact' reservation prices may be quite high and probably much higher than for identifying which option one prefers. Such differences in costs of decision making can explain this response pattern, using economic theory.

${ }^{10}$ The information given to the students is presented in Appendix 1.
} 


\subsection{The tteries}

\subsubsection{Experiment 1: Real lottery tickets}

As already indicated the basic idea in experiment I was to use lottery tickets that are sold regularly on the Swedish market. The following two (state) lotieries have profiles that are interesting from a preference reversal point of view.

The first lottery - used in the role of the \$-bet - is Penninglotteriet, which has some high prizes, e.g. two prices of SEK 1 million. On average only one ticket out of seven wins. ${ }^{11}$ A ticket costs SEK 40. There are draws twice a month, with sales of around 750,000 tickets per draw.

The second lottery - used in the role of the P-bet - is TRISS-lotteriet. Prizes are fairly low, with no prize above SEK 100,000. One ticket out of five wins. A ticket costs SEK 20. Around 6 million tickets are sold each month. Here, the buyer learns whether or not he has won by scraping the surface of the lottery ticket. ${ }^{12}$

In both lotteries the total prize sum amounts to 49 percent of gross revenue.

As the \$-bet in experiment I we used a third of a package of three Penninglotteriet tickets. The P-bet consisted of a third of a package of six Trisslotteriet tickets. For these two packages of lotteries, the probabilities of winning are 0.37 and 0.74 , respectively. ${ }^{13}$ The expected payoff is the same for both packages.

As we wanted the participants to know at the end of the session whether they had won or not, the experinents were carried out after the date of the draw of a $\$$-bet. From a date before the draw and up to the time of the experiment, the lottery tickets were kept scaled in a trustworthy fashion. ${ }^{14}$

\subsubsection{Experiments II: Control experiment}

To compare the outcume of the lottery experiment just described with that of traditional preference reversal experiments, we conducted an additional test, experiment II, with a set of non-market lotteries similar to those used in earlier experiments. This test could also prove useful when trying to indentify

\footnotetext{
${ }^{11}$ The complete prize plans can be found in Appendix 2.

${ }^{12}$ According tc market studies made by the firm administering the lotteries, 78 percent of the population have heard of TRISS-lotteriet, 55 percent know it well and 62 percent have bought tickets in this lottery at least once. The corresponding figures for Penninglotteriet are 90,60 , and 74 percent.

${ }^{13}$ The probability of winning is equal to one minus the proablity of not winning on any of the three or six lottery tickets, respectively. This is, we have $1-(6 / 7)^{3}=0.37$ and $1-(4 / 5)^{6}=0.74$.

14 The participants were informed of that fact that the lottery tickets during this period had been kept in sealed envelope in the safe of a secretary at the department where the participants were students. The secretary then bro ight the tickets directly to the premises of the experiment.
} 
which aspect of the lotteries in experiment I was the cause of a reduction in the number of preference reversals, should such a reduction materialize. ${ }^{15}$

More specifically, the non-market lotteries in experiment II resemble the lotteries in earlier experiments as far as the simplicity of the prize plans is concerned, whereas the probabilities of winning and the expected values were chosen so as to resemble those of the real-world lotteries mentioned above. The \$-bet in experiment II had the same probability of winning as the original \$-bet tickets in experiment I, i.e., 1 in 7. The P-bet had approximately the same probability as a pair of original P-bet tickets, i.e., 2 in 5. Using the probabilities of winning in experiment $I(0.37$ and, in particular, 0.74), would - for reasons stated below - be meaningless here.

If we had used tine same expected value as in the real lotteries, we would have ended up with the following three alternatives:

(1) SEK 40

(2) 1/7 chance of winning SEK 140 (\$-bet)

(3) $2 / 5$ chance of winning SEK 50 (P-bet).

This clearly illustrates the problem of the relevance of the P-bets used in the earlier experiments. Few people can be expected to choose the P-bet in this case. As compared to alternative (1) it means a 3/5 chance of losing SEK 4y and a $2 / 5$ chance of winning SEK 10 ! Preliminary investigations showed that if we raised the expected value of the lotteries by 50 percent all three alternatives would stand a chance of being interesting. The efore, the following alternatives were used in experiment II:

(1) SEK 40

(2) 1/7 chance of winning SEK 210 (\$-bet)

(3) $2 / 5$ chance of winning SEK 75 (P-bet). ${ }^{16}$

\subsection{How the experiments were carried out}

As a first step, forms $1 A$ or $1 B^{17}$ were handed out and participants were told to state in writing which of the three alternatives they would like to receive. These forms include the prize plans along with the probabilities of winning relevant for the two packages of lottery tickets (in experiment I). In

\footnotetext{
${ }^{15}$ This means that experiment II aiffers from the traditional preferance reversal experiments both with respect to object value and experimental setup. If the share of preference reversal turned out to be low in this control experiment, it would be necessary to investigate the :ole of these differences.

${ }^{16}$ In this experiment, the draws were made by taking a marble from a bag with marbles of different colors in proportions representing the chances of the two outcomes in the lotteries.

${ }^{17}$ The difference between $1 \mathrm{~A}$ and $1 \mathrm{~B}$ is that on form $1 \mathrm{~A}$ the $\$$-bet is the first alternative and the P-bet the last, while on 1B the P-bet is presented iirst. The same is true for 2A and $2 \mathrm{~B}$. Those who got A-forms were always informed or asked about the \$-bet before the P-bet, and vice versa for those who got B-forms. All forms are presented in Appendix 2.
} 
addition, we informed the participants about the general characteristics of the two lottery a!ternatıves. After form 1 had been returned, form 2 was handed out. Here, participants were to state which of the remaining two alternatives they would like to receive. ${ }^{18}$

After these forms had been collected, the participants were told that we wanted everyone to be or an equal footing in the next stage of the experiment and that they would therefore receive the remaining third alternative. Participants were then informed that they would be given a chance to sell their lottery tickets and/or buy one more ticket. ${ }^{19}$ For each ticket they should state their minimum selling price (maximum buying price). ${ }^{20}$ Participants were told that the 'market' price for each type of ticket would be the price where there were as many buyers as sellers, and that transactions would take place at this price. They were also told that the procedure was such that there v'as no point in trying to make 'tactical' bids. $^{21}$

After the equilibrium prices had been identified, lottery tickets (or shares of packages of lottery tickets) and cash amounts were distributed to the participants (SEK $40+$ price of tickets sold - price of ticket bought). ${ }^{22}$

\section{Results}

\subsection{Experiment I}

The share of preference reversals in experiment $I$ is presented in table 2. The participants are here divided into three groups reflecting their choice in the first round (money, \$-bet, P-bet). For each group the first part of the table shows the number of participants, the share of participants revealing

\footnotetext{
${ }^{18}$ The full instructons given in various stages of the experiment are available on request from the authors.

${ }^{19}$ The participants :vere given the opportunity to buy only one additional ticket. (Participants seated on edd-numbered chairs were given the chance to buy an additional \$-bet ticket, and those on even-numbered chairs another P-bet ticket.) The reasons for this constraint was to avoid unnecessary complications. In ex-eriment I, participants were informed that buyers of additional tickets would be given two shares in the same package of tickets, not one share in each of two packages. In experiment II, buyers would receive an additional draw.

${ }^{20}$ Form 3 was distributed together with forms $4 A, 4 B$ and $4 C 1(4 C 2)$ for potential S-bet (Pbet) buyers. Selling and buying bids - in even SEK 5 - were to be tated on forms $4 \mathrm{~A}-\mathrm{C}$. Before returning forms $4 \mathrm{~A}-\mathrm{C}$, participants were requested to insert the reservation prices (stated on forms $4 A-C$ ) in form 3 and to keep form 3 for the remainder of the scssion.

${ }^{21}$ Since there is no (calculable) point in mistepresenting reservation prices here, we wanted to gain time by ifplling the participants so. Although our method is such that under very exceptional cir:imstances a small gain could be made by misrepresenting one's bid, the participant has no way of knowing whether these circumstances hold. Under other and more general circumstances, a loss would result from such behavior. Misrepresentations can therefore be expected to lead to losses more often than gains.

${ }^{22}$ For readers interested in the costs of these experiments, Icttery ticket expenses and cash paid to the participants added up to some SEK 17000 . Administra iiva assistance (or habor input aside from planning and evaluating the experiment) amounted to some 30 man-hour:
} 
Table 2

Preference reversal and choice/price consistency: Experiment 1.

\begin{tabular}{lllll}
\hline & Number & & Preference reversal & \multicolumn{2}{l}{ Choice/price consistency with } \\
\cline { 2 - 5 } & & (percent) & $\begin{array}{l}\text { Different prices } \\
\text { (percent) }\end{array}$ & $\begin{array}{l}\text { Identical prices } \\
\text { (percent) }\end{array}$ \\
\hline Money first & 15 & 13 & 33 & 53 \\
S-bet first & 48 & 6 & 65 & 29 \\
P-bet first & 23 & 22 & 22 & 56 \\
\$-bet $>$ P-bet & 56 & 5 & 59 & 36 \\
P-bet $>$ S-bet & 30 & 23 & 27 & 50 \\
S-bet G \& P & - & 13 & - & - \\
P-bet G \& P & - & 70 & - & - \\
S-bet PS \& Z & - & 12 & - & - \\
P-bet PS \& Z & - & 45 & - & - \\
\hline
\end{tabular}

preference reversal, the share stating a higher reservation price for the preferred bet, and the share stating the same reservation price for the two bets. The total results for the two orders of preferences over lotteries, independently of the preferences for money, are shown on lines four and five. The last four lines of the table list results from two earlier studies: the seminal study by Grether and Plott (1979) and a rsplication made by Pommerehne, Schneider and Zweifel (1982).

We focus first on the groups that chose P-bets over \$-bets, which is where preference reversal has been most prominent in earlier studies. ${ }^{23}$ The share of preference reversal in this group was 23 percent. This share is significantly lower than those observed in G\&P as well as PS\&Z. The share of preference reversal in the present study lies outside a 95 percent confidence interval (derived from the binomial distribution) assuming that the true share was the relatively low one observed by PS \& Z.

Of those choosing \$-bets over P-bets, only 5 percent stated inconsistent responses. With a share as low as this, preference reversal in this group cannot convincingly be said to deviate from zero. in ail, 3 subjects out of $56_{0}$ gave inconsistent responses. Pure misunderstandings, and misłakes in filling out the forms, could clearly account for preference reversal on this order of magnicude.

Adding the two groups, the share of preference reversal was as low as 11 percent. This can be compared to overail shares of 36 percent and 27 percent in the $G \& P$ and $P S \& Z Z$ studies, respectively.

To test whether or not preference reversal is more common among 'uninterested' subjects, i.e., those who preferred money in the first round (in

\footnotetext{
${ }^{23}$ In some studies, notably those by Lichtenstein and Slovic, the point of departure was that of a 'theory of anchoring and adjustment', on the basis of which preierence reversal is predicted in grours that chose P-bets over \$-bets and in such groups only.
} 
Table 3

'Interested' vs. 'uninterested' subjects: Experiment I.

\begin{tabular}{|c|c|c|c|c|}
\hline \multirow[t]{2}{*}{ Order of choice } & \multirow[t]{2}{*}{ Number } & \multirow{2}{*}{$\begin{array}{l}\text { Preference reversal } \\
\text { (percent) }\end{array}$} & \multicolumn{2}{|c|}{ Choice/price consistency with } \\
\hline & & & $\begin{array}{l}\text { Different prices } \\
\text { (percent) }\end{array}$ & $\begin{array}{l}\text { Identical prices } \\
\text { (percent) }\end{array}$ \\
\hline $\begin{array}{l}\text { M-S-P } \\
\because-P-M \\
(\$-M-P)\end{array}$ & $\begin{array}{r}8 \\
36 \\
(12) \\
=56\end{array}$ & $\begin{array}{c}0 \\
6 \\
(8)\end{array}$ & $\begin{array}{c}25 \\
58 \\
(83)\end{array}$ & $\begin{array}{l}75 \\
36 \\
(8)\end{array}$ \\
\hline $\begin{array}{l}\text { M-P-S } \\
\text { P-S-M } \\
(P-M-\$)\end{array}$ & $\begin{aligned} & 7 \\
& 19 \\
&(4) \\
&=30\end{aligned}$ & $\begin{array}{l}29 \\
26 \\
(0)\end{array}$ & $\begin{array}{r}43 \\
5 \\
(75)\end{array}$ & $\begin{array}{c}29 \\
68 \\
(25)\end{array}$ \\
\hline
\end{tabular}

Table 4

Preference reversal and choice/price consistency: Experiment II.

\begin{tabular}{lllll}
\hline & Number & Preference reversal & Choice/price consistency with \\
\cline { 2 - 5 } & & (percent) & $\begin{array}{c}\text { Different prices } \\
\text { (percent) }\end{array}$ & $\begin{array}{l}\text { Identical prices } \\
\text { (percent) }\end{array}$ \\
\hline Money first & 22 & 50 & 46 & 4 \\
S-bet first & 15 & 0 & 100 & 0 \\
P-bet first & 20 & 70 & 5 & 25 \\
S-bet $>$ P-bet & 24 & 4 & 96 & 0 \\
P-bet $>$ S-bet & 33 & 73 & 9 & 18 \\
\hline
\end{tabular}

the order M-\$-P or M-P-\$), we compare them with those who chose money last (\$-P-M and P-\$-M, respectively). The first two lines of table 3 show those who preferrea the \$-bet over the P-bet (M-\$-P and \$-P-M); lines 4 and 5 show those who preferred the P-bet over the \$-bet (M-P-\$ and P-\$-M). We omit those choosing money in stage 2 from the analysis (see lines 3 and 6).

The results indicate that there is no sigir ant difference in the rate of preference reversal between 'lottery-interested' (money last) and 'not lottery interestid' (money first) subjects. Among those who chose the \$-bet over the P-bet, the frequency of preference reversal is about the same for the two groups -0 and 6 percent respectively. This is also the case among those who chose the P-bet over the \$-bet, where preference reversal is 26 and 29 percent, respectively. Thus, the important difference is still between those who chose the P-bet over ine \$-bet and those who chose the \$-bet over the P-bet, regardless of whether money was chosen first or last.

\subsection{Experiment II}

The results of experiment II are shown in table 4. As can be seen from the 
Table 5

'Interested' vs. 'uninterested' sLbjects: Experiment II.

\begin{tabular}{|c|c|c|c|c|}
\hline \multirow[t]{2}{*}{ Order of choice } & \multirow[t]{2}{*}{ Number } & \multirow{2}{*}{$\begin{array}{l}\text { Preference reversal } \\
\text { (percent) }\end{array}$} & \multicolumn{2}{|c|}{ Choice/price consistency with } \\
\hline & & & $\begin{array}{l}\text { Different prices } \\
\text { (percent) }\end{array}$ & $\begin{array}{l}\text { Identical prices } \\
\text { (percent) }\end{array}$ \\
\hline $\begin{array}{l}\text { M-\$-P } \\
\text { \$-P-M } \\
(\$-M-P)\end{array}$ & $\begin{array}{r}9 \\
5 \\
(10) \\
=24\end{array}$ & $\begin{array}{c}11 \\
0 \\
(0)\end{array}$ & $\begin{array}{r}89 \\
100 \\
(100)\end{array}$ & $\begin{array}{c}0 \\
0 \\
0\end{array}$ \\
\hline $\begin{array}{l}\text { M-P-\$ } \\
\text { P-S-M } \\
\text { (P-M-\$) }\end{array}$ & $\begin{array}{r}13 \\
5 \\
(15) \\
=33\end{array}$ & $\begin{array}{c}77 \\
80 \\
(67)\end{array}$ & $\begin{array}{l}15 \\
20 \\
(0)\end{array}$ & $\begin{array}{c}8 \\
0 \\
(33)\end{array}$ \\
\hline
\end{tabular}

table, they are much in line with those of earlier studies such as Grether and Plott (1979). The fact that probabilities of winning and expected values in our test were comparable to large real-world lotteries did not affect the share of preference reversal. Moreover, when the choice and statement of the reservation prices were moved closer in time, with no other choices in bet'veen, contrary to most earlier experiments, the share of preference reversal was not reduced. The question remains as to whether or not the high share of preference reversal in experiment II, as compared to experiment $I$, is caused by the differences in prize plans or the niere fact that the lotteries in experiment II were unfamiliar to the participants.

We may also note that, in contrast to the real-world lotteries of experiment I, and in line with mos! lotteries used in earlier studies, P-bets are chosen before \$-bets in most of the cases. In experiment II, P-bets were the first lottery choice in 58 percent of the cases as compared to only $\mathbf{3 5}$ percent for experiment $I$.

Table 5 shows that just as in experiment $I$, the results do not indicate that preference reversal is more common among those who chose money first. In this case as weil, the significant difference is between those who choose the P-bet before the \$-bet and those who choose the \$-bet before the P-bet, regardless of whether money is chosen first or last.

We should note that no one who preferred money to lotteries (i.e., 'uninterested' subjects) in experiment I or II stated buying prices above SEK $40{ }^{24}$ The median buying prices stated by this group, with the exception of P-bets in experiment II, were lower thail those stated by the group who chose a lottery ticket first ('interested subjects'). Of course, this kind of behavior is to be expected from those whom we regard as 'uninterested' vs. 'interested' decision-makers.

${ }^{24}$ The distribution of the buying and seling prices is given in Appendix 3. 
From a comparison of the reservation prices in experiments $I$ and it it appears that a lottery loses some of its attraction when a few high prizes are replaced by a large numbur of low prizes, with the expected payoff remaining the same or - as here - somewhat higher. A reasonable hypothesis is that the less attractive the lotteries, the greater the frequency of pure mistakes in decision making, and hence of false preference reversals. This is supported by our results. If behavior, whereby a subject chooses a lottery ticket before SEK 40, but states a seliing nrice below SEK 40 for this ticket, is interpreted as a pure mistake we can note that, in experiment $I$, only one subject out of 71 behaved in this fashion, whereas with the less attractive lotteries of experiment II, the number of such 'mistakes' increased to 8 out of $36 .{ }^{25}$

\subsection{Some comments}

The frequency of stating the same reservation price for both lotteries

In the experiment with real-world lotteries, the share of participants who stated the same reservation price for the lottery tickets was rather high (42 percent). The fact that the packages of lottery tickets can be evaluated using given market prices and, if so, come out the same, is likely to play a role here. This is supported by the lower number of subjects who state the same price in experiment II, wher no information can be provided in terms of given market prices. It should be observed, however, that the level of the market prices in experiment I did not play any significant role in determining the selling prices (see Apper dix 3).

\section{Possible 'portfolio effects'}

In section 2 we noted that differences between choice and ranking of selling prices in our experiments could arise from changes in the composition of the individual's wealth between the first part of the experiments, where choices are made, and the second part, where reservation prices are stated. We pointed out that an individual who chooses the P-bet first may prefer SEK $40+\$$-bet to SEK $40+P$-bet at the pricing stage, anú therefore set a lower reservation price for the P-bet. In other words, the risikier \$-bet may be preferred when the subject knows - which is the case at the pricing stage that he will receive SEK 40 in cash. Let us look at our results in the light of this possibility.

First, if some of the observed preference reversals were caused by portfolio

\footnotetext{
${ }^{25}$ In prin $\therefore$ ple, this behavior could be caused by income effects and lottery tickets being an inferior gnod.
} 
effects of the type just described, the share of 'pure' preference reversal would be even lower than that reported in section 5.1. Thus, our tentative conclusion that the use of real-world lotteries (as compared to one-prize lotteries with expected values of the same order of magnitude) leads to a lower share of preference reversal would, if anything, be strengthened by the possibility of such 'spurious' preference reversals.

Second, it is important to note that preference reversals cannot be fully explained by portfolio effects. In fact, preference reversals were as frequent in group $\mathbf{M}$-P-\$, where no portfolio effects can arise, as in group P-\$-M. ${ }^{26}$

\section{The relevance of the procedure invariance hypothesis}

The most popular theory about the causes of preference reversal seems to be the 'procedure invariance hypothesis', according to which the procedure of eliciting preferences can affect the preferences observed [see, e.g., Tversky et ai. (1990) and Tversky and Thaier (1990)]. An earlier version of this theory states that responses tend to be 'anchored' in a salient feature of the lottery, seemingly the most relevant for the question raised, and then 'adjusted' when other features of the lottery are noted. Thus, when asked about (relative) reservation prices, relative prizes would come to mind first, while probabilities would play a secondary role. It is obvious that this version of the theory is hardly applicable to real-world lotteries where the $e$ is no one prize to which a price judgment could be anchored.

Tversky et al. (1990) present results from a set of tests interpreted as supporting the procedure invariance hypothesis. However, these tests are questionable for several reasons (as noted in footnote 3). For example, they analyze primarily hypothetical choices or use trivial incentives. Moreover, there is no market where selling reservation prices can play a role.

\section{Summary and concluding comments}

(1) We have seen that even when real-world lotteries are used as choice objects, preference reversal appears with some frequency. In our experiments, the overall frequency was 11 percent.

(2) This frequency, however, is significantly lower than that observed in earlier experiments using non-market lotteries.

(3) There was no difference in preference reversal between lottery-interested and lottery-uninterested subjects, where lottery interest was defined by the subjects' choice of lotteries over money.

\footnotetext{
${ }^{26}$ As portfolio effects can arise only among 'inierested' subjects, the existence of significant portfolio effects would reopen the case for preference reversal as a phenomenon primarily among those who are not 'interested".
} 
(4) As in earlier lottery tests, preference reversal occurred primarily for those who chose P-bets over \$-bets. The frequency was 23 percent in this group (experiment I).

(5) Preference reversal was so rare among those who chose \$-bets over Pbets ( 3 out of 56) that, for this group, preference reversal does not exceed what can be expected as a result of pure mistakes.

(6) The group where preference reversal is most often observed (where Pbets are chosen over \$-bets) has been dominant in many previous tests using non-market lotteries. For the real-world lotteries used in experiment $I$, this group accounted for only 35 percent. A possible explanation is that people tend to shift to a preference for the \$-bet if the prize range is widened, i.e., if the (higher) prizes become more spectacular.

(7) Thus, the overall low frequency of preferences reversal for real-world lotteries is explained by the fact that (i) preference reversal is less frequent in the group where it constitutes a (significant) problem, viz. those who choose P-bets over \$-bets, and (ii) this group is smaller for real-world lotteries than for lotteries of the type used in earlier experiments.

Comparing the real-world lottery experiment (experiment I) with an earlier test of choice/price consistency using real-world payoff-uncertain objects (used cars), where no preference reversal was found [Bohm (1991)], the question centers on the reason for this difference. A number of candidates can be listed: known vs unknown object prices, known vs unknown probabilities, objects with actual market prices aroung $\$ 7$ or $\$ 1,000$, outcomes expressed in monetary units or not, and the presence vs absence of pure gambling.

\section{Appendix 1: Information to prospective participants}

The following information was given to the prospective participants:

$\therefore$... (general introduction) ... We are running a series of experiments to increase our understanding of people's behavior under uncertainty, that is, how people choose among objects, the values of which are not known in advance. Since many objects are of this type - stocks, used cars, durable consumer goods, etc. - economists have become more and more interested in how people behave when the consequences of choosing a certain alternative are uncertain.

We are planning an experiment where you are invited to participate. If you do, you would not only contribute to increasing our knowledge, but also earn some money. How much depends partly on your own choices, partly on chance - as just mentioned, we are intereted in behavior under uncertainty.

An experiment will be held on date $X$ in room $Y$. It is expected to last one hour and a half. If you want to participate you can sign one of the lists that are now being circulated. . ' 
Forms for experiment I are shown here. Those used in experiment II were similar.

Form 1A

\section{Check what you prefer to obtain:}

A third of three 'Penninglotter', ticket price SEK $\mathbf{4 0}$

SEK 40

A third of six 'Trisslotter', ticket nrice SEK 20

signature

Prize plans

\section{PENNING}

\section{LOTTERIET}

The ticket price is SEK 40. ... On the average you win on one ticket out of seven

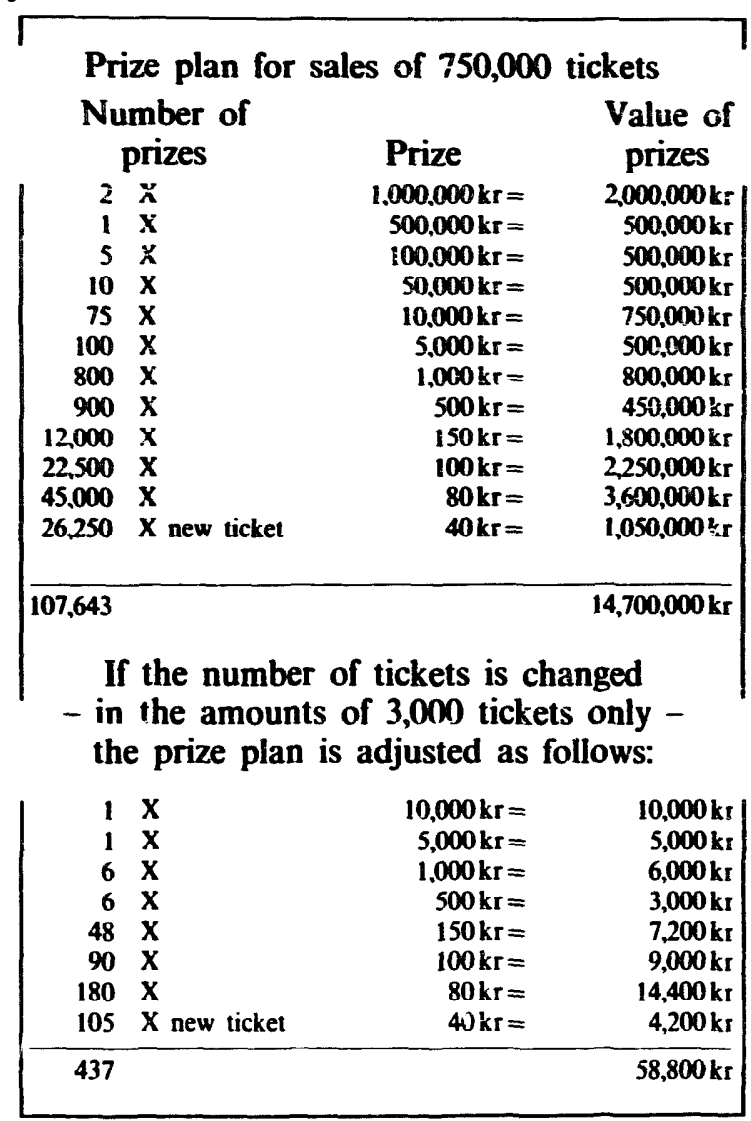

\section{TRISS}

... each ticket is SEK 20. ... On the average you win on every fifth ticket

Prize plan for sales of $6,000,000$ tickets (the prize plan is adjusted pruportionally to changes in sales)

\begin{tabular}{|ccc|}
$\begin{array}{c}\text { Number of } \\
\text { prizes }\end{array}$ & $\begin{array}{c}\text { Prize } \\
60 \mathrm{X}\end{array}$ & $\begin{array}{c}\text { Value of } \\
\text { prizes }\end{array}$ \\
$600 \mathrm{X}$ & $100,000 \mathrm{kr}=$ & $6,000,000 \mathrm{kr}$ \\
$2400 \mathrm{X}$ & $10,000 \mathrm{kr}=$ & $6,000,000 \mathrm{kr}$ \\
$45,000 \mathrm{X}$ & $1,00 \mathrm{kr}=$ & $2400,000 \mathrm{kr}$ \\
$180,000 \mathrm{X}$ & $100 \mathrm{kr}=$ & $4,500,000 \mathrm{kr}$ \\
$482,700 \mathrm{X}$ & $2 \mathrm{kr}=$ & $10,800,000 \mathrm{kr}$ \\
$489,600 \mathrm{X}$ & $40 \mathrm{kr}=$ & $19,308,000 \mathrm{kr}$ \\
\hline $1,200,360$ & $20 \mathrm{kr}=$ & $9,792,000 \mathrm{kr}$ \\
\hline
\end{tabular}

The chance of winning any prize is 4 in 10 with a package of 'Penninglotter', while the chance is 8 in 10 with a package of Trisslotter. The size of the average prize is higher for the 'Penninglotter'-package - double that of the 'Trisslotiter'-package.

[For simplicity, the probabilities were rounded off: 0.37 to 0.4 and 0.74 io 0.8 . The latter figure was chosen to keep the correct relation between the lotteries.] 
Form 2A

This form contains the same set of alternatives as the preceding form.

Cross out the alternative tinat you have just chosen.

Check which one of the two remaining alternatives that yyu prefer to obtain.

A third of three 'Penninglotter", ticket price SEK 40

SEK 40

A third of six 'Trisslotter', ticket price SEK 20

signature

[The rest of this form was identical to the second half of form 1A.]

Form $3 \mathrm{~A}$

Summary statement:

So far you have obtained:

A third of three 'Penninglotter', ticket price SEK 40

A thrd of six 'Trisslotter', ticket price SEK 20

SEK 40

Now please turn to the next form. We will return later to the points below.

The lowest price that I wanr to SEI.L a third of three 'PENNINGlotter' for is:

SEK.......

The lowest price that I want to SELL a third of six 'TRISSlotter' for is:

SEK.......

The highest price that I want to PAY a another third of three 'PENNINGlotter' is:

SEK....... 


\section{Form $4 \mathrm{~A}$}

Are you interested in selling your third of the package of three 'PENNINGlotter'?

$\begin{array}{lll} & \text { YES, } & \text { NO } \\ \text { IIl sell if } & \text { I won't sell if } \\ \text { the price is } & \text { (Please check) } & \text { the price is } \\ \text { PRICE, SEK } & \text { (Please check) }\end{array}$

120

115

110

15

10

5

If you are not willing to sell at any of these prices, state the lowest price that you are willing to sell for, rounded off to even SEK 5:

I wish to sell my third of the three 'Penninglotter' if the price is at least SEK.....

signature

\section{Form $4 \mathrm{Cl}$}

Are you interested in buying another third of the package of three 'PENNINGlotter'?

$\begin{array}{lll} & \text { YES, } & \text { NO } \\ \text { I'll buy if } & \text { I won't buy if } \\ \text { the price is } & \text { the price is } \\ \text { (Please check) } & \text { (Please check) }\end{array}$

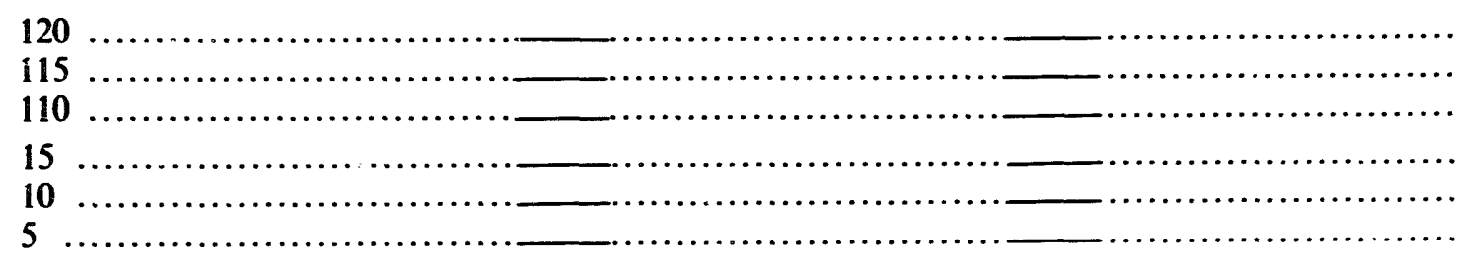


Appendix 3: Distribution of reservation prices

Experimen' I, selling prices.

\begin{tabular}{|c|c|c|c|c|c|c|}
\hline \multirow[b]{3}{*}{ SEK } & \multicolumn{6}{|c|}{ First choice } \\
\hline & \multicolumn{2}{|l|}{ S-bet } & \multicolumn{2}{|l|}{ P-bet } & \multirow{2}{*}{$\frac{\text { money }}{\text { \$-bet }}$} & \multirow{2}{*}{ P-bet } \\
\hline & \$-bet & P-bet & \$-bet & P-bet & & \\
\hline$<35$ & 0 & 2 & 0 & 0 & 4 & 5 \\
\hline 35 & 1 & 0 & 0 & 0 & 1 & 2 \\
\hline 40 & 1 & 2 & 2 & 2 & 4 & 1 \\
\hline 45,50 & 5 & 11 & 5 & 3 & 3 & 3 \\
\hline 55.60 & 5 & 5 & 0 & ? & 1 & 2 \\
\hline 65.70 & 2 & 5 & 2 & 2 & 0 & 0 \\
\hline 75,80 & 6 & 2 & 2 & 3 & 1 & 1 \\
\hline 85,90 & 2 & 4 & 1 & 1 & 0 & 0 \\
\hline 96,100 & 10 & 11 & 2 & 2 & 0 & 1 \\
\hline $105-120$ & 3 & 3 & 3 & 3 & 1 & 0 \\
\hline $125-150$ & $i$ & 0 & 0 & 0 & 0 & 0 \\
\hline $155-200$ & 4 & 0 & 0 & 0 & 0 & 0 \\
\hline$>200$ & 8 & 3 & 6 & 5 & 0 & 0 \\
\hline Sum & 48 & 48 & 23 & 23 & 15 & 15 \\
\hline Median & 100 & 70 & 85 & 80 & 40 & 40 \\
\hline
\end{tabular}

Experiment I, buying prices.

First choice

\begin{tabular}{lcccccc} 
& S-bet & \multicolumn{3}{c}{ P-bet } & \multicolumn{2}{c}{ money } \\
SEK & S-bet & P-bet & S-bet & P-bet & S-bet & P-bet \\
\hline 15 & 3 & 1 & 1 & 0 & 2 & 4 \\
15,20 & 4 & 3 & 1 & 3 & 1 & 2 \\
25,30 & 4 & 4 & 1 & 1 & 0 & 2 \\
35 & 2 & 2 & 0 & 0 & 1 & 0 \\
40 & 11 & 8 & 5 & 4 & 2 & 1 \\
45 & 1 & 1 & 1 & 1 & 0 & 0 \\
50 & 1 & 1 & 2 & 2 & 0 & 6 \\
55 & 1 & 0 & 1 & 0 & 0 & 0 \\
60 & 0 & 1 & 0 & 0 & 0 & 0 \\
Sum & 27 & 21 & 12 & 11 & 6 & 9 \\
Median & 40 & 40 & 40 & 40 & 28 & 15
\end{tabular}


Experiment II. selling prices.

\begin{tabular}{|c|c|c|c|c|c|c|}
\hline \multirow[b]{3}{*}{ SEK } & \multicolumn{6}{|c|}{ First choice } \\
\hline & \multicolumn{2}{|l|}{ S-bet } & \multicolumn{2}{|l|}{ P-bet } & \multicolumn{2}{|l|}{ money } \\
\hline & S-bet & P-bet & S-bet & P-bet & S-bet & P-bet \\
\hline$<35$ & 1 & 3 & 2 & 6 & 4 & 10 \\
\hline 35 & 0 & 2 & 1 & 1 & 3 & 5 \\
\hline 40 & 1 & 4 & 5 & 7 & 3 & 3 \\
\hline 35,50 & 4 & 7 & 6 & 3 & 3 & 3 \\
\hline 55.60 & 1 & 0 & 2 & 2 & 2 & 1 \\
\hline 65,70 & 1 & 0 & 1 & 0 & 2 & 0 \\
\hline 75,80 & 2 & 0 & 2 & 0 & 4 & 0 \\
\hline 85,90 & 1 & 0 & 0 & 0 & 0 & 0 \\
\hline 95,100 & 4 & 0 & 1 & 1 & 1 & 0 \\
\hline$>100$ & $i$ & 0 & 0 & 0 & 0 & 0 \\
\hline Sum & 16 & 16 & 20 & 20 & 22 & 22 \\
\hline Median & 72 & 40 & 50 & 40 & 50 & 35 \\
\hline
\end{tabular}

Experiment II. buying prices.

\begin{tabular}{|c|c|c|c|c|c|c|}
\hline \multirow[b]{3}{*}{ SEK } & \multicolumn{6}{|c|}{ First choice } \\
\hline & \multicolumn{2}{|l|}{ S-bet } & \multicolumn{2}{|l|}{ P-bet } & \multirow{2}{*}{$\begin{array}{c}\text { money } \\
\text { S-bet }\end{array}$} & \multirow[b]{2}{*}{ P-bet } \\
\hline & S-bet & P-bet & S-bet & P-bet & & \\
\hline$<15$ & 1 & 2 & 3 & 2 & 3 & 2 \\
\hline 15,20 & 0 & 3 & 2 & 3 & 3 & 6 \\
\hline 25,30 & 2 & 3 & 3 & 2 & 2 & 4 \\
\hline 35 & 2 & 0 & 2 & 0 & 1 & 0 \\
\hline 40 & 2 & 1 & 1 & 1 & 1 & 0 \\
\hline 45 & 0 & 0 & 0 & 0 & 0 & 0 \\
\hline 50 & 0 & 0 & 1 & 0 & 0 & 0 \\
\hline Sum & 7 & 9 & 12 & 8 & 10 & 12 \\
\hline Median & 35 & 15 & 25 & 18 & 20 & 20 \\
\hline
\end{tabular}




\section{References}

Berg, Joyce E., John W. Dickhaut and John R. O'Brien, 1985, Preference reversal and arbitrage, in: Vernon L. Smith, ed., Research in experimental economics, vol. 3 (JAI Press, Greenwich).

Bohm, Peter, 1991, Bshaviour under uncertainty without preference reversal: A field experiment, forthcoming in Empirical Economics.

Bostic, Raphael, Richard J. Herrnstein and R. Duncan Luce, 1990, The effect on the preferencereversal phenomenon of using choice indifferences. Journal of Econumic Behavior and Organization 13, 193-212.

Cox, James C. and Seth Epstein, 1989, Preference reversal without the independence axiom, American Economic Review 79, 408-426.

Grether, David M. and Charles R. Plott, 1979, Economic theory of choice and the preference reversal phenomenon, American Economic Review 69, 623-638.

Harrison, Glenn W., 1989, Theory and misbehavior of first-price auctions, American Economic Review 79, 749-762.

Harrison, Glenn W., 1989b, The payoff dominance critique of experimental economics, Mimeo. (University of New Mexico).

Kahneman, Daniel, Jack Knetsch and Richard H. Thaler, 1990, Experimental test of the endowment effect and the Coase theorem, Journal of Political Economy 98, 1325-1348.

Karni, Edi and Zvi Safra, 1987, Preference reversal and the observability of preferences by experimental methods, Econometrica 55, 675-685.

Lichtenstein, Sarah and Paul Slovie, 1971, Reversals of preferences between bids and choices in gambliag decisions, Journal of Experimental Psychology 89, 46-55.

Lichtenstein, Sarah and Paul Stcvic, 1973, Response-induced reversals of preferences in gambling An extended replication in Las Vegas, Journal of Experimental Psychology 101, 16-20.

Pommerehne, Werner W., Friedreich Schneider and Peter Zweifel, 1982, Economic theory of choice and the preierence reversal phenomenon: A reexamination, American Economic Rericw 72, 569-574.

Slovic, Pau! and Sarah Lichtenstein, 1968, The relative importance of probabilities and payoffs in risk-taking, Journal of Experimental Psy hoiogy Monograph Supplement 78, 1-18.

Tversky; Amos, Paul Slovic and Daniel Kahneman, 1990, The causes of preference reversal, American Economic Review 80, 204-218.

Tversky, Amos and Richard H. Thaler, 1990, Anomalies: Preference reversal, Journal of Economic Luterature 4, 201-211. 